\title{
Beauty Beneath the Waters
}

By Hugh McLaughlen, Lewvan.
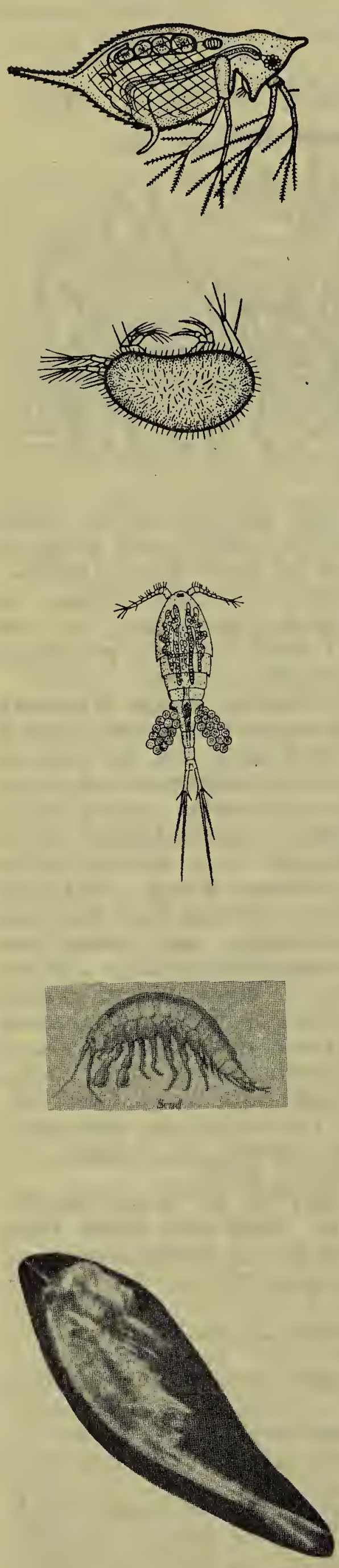

SOMETIMES when the pursuit of an acquaint. anceship with the Red-wing Blackbirds or the white flowers of the Canada Anemone have lured one to a watering place, and shade and rest are next in order, be careful not to sit under a bridge or look too closely into the waters of the wayside ditches, or you too will probably become an addict -and join the agua-sites.

Avert your eyes from the tiny clams threshing about in the shallow water, the "Apies" rooting along in the mud under ten or fifteen inches of water and the other dozens of denizens. But one's feet generally get wet anyway so we will look for a few minutes at the posts supporting the bridge and the odd corner of the planking.

A brightly colored fish seems to cling to a portion of the woodwork, and swim up and down, up and down, across-now darting away in fright as you peer closer, but always returning. As he rolls over, the sun glints on his side, showing alternating bands of black and orange-a sort of cushion effect on the top of head and back, and points dotted over a blunt nose.

The fish has a deposit of eggs- 50 to 100 -the size of pin heads glued to whatever stable object is available. These it is aerating and guarding jealously. I have observed five or more nests on a single tomato car and there is a continual chasing and counter-chasing-sparring and racing among these small fry-- three and four inch minnows.

A minnow now, with silver coloring and black streak along each side, joins one of the pugnacious ones and they swim actively close together in the vicinity of the nest-a fertilizing process I would imagine. These silver ones do not stay long in the vicinity. They flit about but stay out of sight most of the time. I thought they were a different species until the mating activities were observed, but they still lack a proper name in my knowledge; perhaps someone can enlighten me.

I have caught the young in January when they were two thirds of an inch long. Young and old live well in aquaria. I kept one fish over three years.

The pugnacious stickleback minnow is harder to keep. If kept together the stickleback will generally get hungry and kill the blunt-nose and then die. If not fed some small game from a pond -a little beef does in a pinch-but who is going to feed pearls to oysters. Eeef prices put it in the jewelry class.

But over here in the ditch is a peculiar creature, swimming on its back, propelled by waving gills-a fairy shrimp. But enough, if you want to keep your feet dry. 